\title{
The Efficient Market Hypothesis and Insider Trading on the Stock Market
}

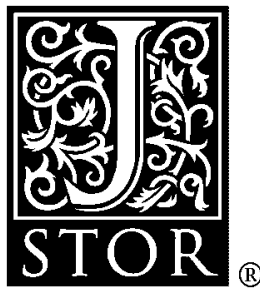

\author{
Jean-Jacques Laffont; Eric S. Maskin
}

The Journal of Political Economy, Vol. 98, No. 1. (Feb., 1990), pp. 70-93.

Stable URL:

http://links.jstor.org/sici?sici=0022-3808\%28199002\%2998\%3A1\%3C70\%3ATEMHAI\%3E2.0.CO\%3B2-W

The Journal of Political Economy is currently published by The University of Chicago Press.

Your use of the JSTOR archive indicates your acceptance of JSTOR's Terms and Conditions of Use, available at

http://www.jstor.org/about/terms.html. JSTOR's Terms and Conditions of Use provides, in part, that unless you have obtained prior permission, you may not download an entire issue of a journal or multiple copies of articles, and you may use content in the JSTOR archive only for your personal, non-commercial use.

Please contact the publisher regarding any further use of this work. Publisher contact information may be obtained at http://www.jstor.org/journals/ucpress.html.

Each copy of any part of a JSTOR transmission must contain the same copyright notice that appears on the screen or printed page of such transmission.

The JSTOR Archive is a trusted digital repository providing for long-term preservation and access to leading academic journals and scholarly literature from around the world. The Archive is supported by libraries, scholarly societies, publishers, and foundations. It is an initiative of JSTOR, a not-for-profit organization with a mission to help the scholarly community take advantage of advances in technology. For more information regarding JSTOR, please contact support@ jstor.org. 


\title{
The Efficient Market Hypothesis and Insider Trading on the Stock Market
}

\section{Jean-Jacques Laffont}

University of Toulouse

\section{Eric S. Maskin}

Harvard University

\begin{abstract}
We study the behavior of a large trader with private information about the mean of an asset with a risky return. We argue that if the variability of the return is not too great, typically the trader will find it desirable to ensure that the market price does not reveal his information, that is, that a "pooling" equilibrium arises. Such an equilibrium has the advantage of avoiding the incentive constraints that arise in "separating" equilibria, where information can be inferred from prices. Thus the efficient market hypothesis may well fail if there is imperfect competition. Despite the uninformativeness of prices, the other (competitive) traders are also better off in the pooling equilibrium than in any separating equilibrium, again if one assumes limited variability.
\end{abstract}

\section{Introduction}

The efficient market hypothesis holds that in markets with significant informational asymmetries (e.g., securities markets) equilibrium prices aggregate information effectively. Thus a trader can infer all he needs to know about others' information simply from observing prices.

Most theoretical examinations of this hypothesis (e.g., Grossman 1976; Radner 1979; Allen 1981) have posited perfect competition, in which individual traders are too small to affect market prices. By and large this literature has confirmed the informational efficiency of 
markets: As long as there are "enough prices" (i.e., trade can be made contingent on sufficiently many events), competitive equilibrium is generically "separating" in the sense that the function relating information to prices is invertible. Imperfect competition adds a new complication to the efficient market question because, when some traders are large, the amount of information conveyed by prices is to some degree a matter of their strategic choice. In fact, we shall argue that, when traders have rational expectations, there are good reasons to believe that the efficient market hypothesis breaks down with imperfect competition. A large trader will typically find it advantageous to conceal his private information parameter by ensuring that the equilibrium price is not sensitive to local variations in this parameter; that is, he will induce an equilibrium of a (locally, at least) "pooling" nature.

Suppose that the large trader's parameter $\tilde{\theta}$ is positively correlated with the mean value of a particular asset. At first sight, the bias in favor of a pooling equilibrium for this asset-one in which the same price emerges for both high and low values of $\tilde{\theta}$-may seem puzzling. If the large trader is a net buyer of the asset, a pooling equilibrium has the apparent advantage that he can buy the asset for less than in a separating equilibrium if $\tilde{\theta}$ is high (since in the pooling equilibrium the market price corresponds to an average of the high and low values of $\tilde{\theta})$. But by the same token, he must pay more than in the separating equilibrium when $\tilde{\theta}$ is low. Thus it might seem as though either a pooling or a separating equilibrium could be better depending on the particular utility functions, probabilities, and so forth.

Actually, however, rational expectations require that, in pooling and separating equilibria, the expected price paid by the large trader be (approximately) the same. The reason is that if the sellers (small traders) are price takers, the market price simply equals their "marginal cost" of selling (i.e., their marginal disutility). Thus if $\tilde{\theta}$ takes on the values $\theta_{1}$ and $\theta_{2}$ with probabilities $\pi_{1}$ and $\pi_{2}$, the prices in a separating equilibrium are $p\left(\theta_{1}\right)=\operatorname{MC}\left(\theta_{1}\right)$ and $p\left(\theta_{2}\right)=\operatorname{MC}\left(\theta_{2}\right)$, and in a pooling equilibrium, the price is $p=\pi_{1} \mathrm{MC}\left(\theta_{1}\right)+\pi_{2} \mathrm{MC}\left(\theta_{2}\right)$. In either case, the expected price is $\pi_{1} \operatorname{MC}\left(\theta_{1}\right)+\pi_{2} \operatorname{MC}\left(\theta_{2}\right)$. (The qualification of approximate equality is made above because, in general, the marginal costs depend on the quantity sold, and, moreover, the equation $p=\pi_{1} \operatorname{MC}\left(\theta_{1}\right)+\pi_{2} \operatorname{MC}\left(\theta_{2}\right)$ implies risk neutrality on the part of the sellers. However, the approximation is good enough when $\theta_{1}$ and $\theta_{2}$ are close.)

Thus the important difference between separating and pooling equilibria lies not with prices but rather with quantities. In a pooling equilibrium, the large trader can buy all he wants at the market price (given the presumed linearity of the small traders' disutility). But this 
cannot be the case in a separating equilibrium because, in such an equilibrium, the price of the asset is low when the value of $\theta$ is low. If the large trader could buy all he wanted at such a price, he would see to it that the price was always low, violating the hypothesized separating nature of equilibrium. Hence, the trader must be quantityconstrained at the low price. This incentive constraint implies that, on average, he cannot buy as much in a separating equilibrium as in a pooling equilibrium. Hence, he will favor the pooling equilibrium.

This simple argument assumed linear preferences on the part of sellers. However, it is suggestive of the general argument, which we provide below in proposition 6 . For similar reasons it follows that just as the large trader prefers pooling, so do the other traders (proposition 9).

There is quite a substantial empirical literature on large trader behavior in asset markets (see Niederhoffer and Osborne 1966; Lorie and Niederhoffer 1968; Kraus and Stoll 1972; Scholes 1972; Grier and Albin 1973; Jaffe 1974; Dann, Mayers, and Raab 1977; Baesel and Stein 1979), but relatively few theoretical investigations. One set of papers assumes that the large trader can commit to a strategy ex ante (i.e., before the informational parameters have been realized). The solution concept is therefore Stackelberg equilibrium. Gould and Verrecchia (1985) develop a static model with a single risk-neutral large trader with private information (a specialist) and many riskaverse small traders. The specialist sets a price, and the others choose the quantities they wish to trade at this price. Pricing strategies are restricted to be linear in information with additive noise. It is found that, when the small traders also possess private information, the specialist profits by garbling his information (taking the noise term to be nondegenerate). When only the specialist has private information, he is hurt by adding noise. Grinblatt and Ross (1985) examine a similar model that also features a set of irrational or "noise" traders. Like Gould and Verrecchia, they restrict their analysis to linear strategies and find that introducing noise is not optimal. Cripps (1986) demonstrates that this result may rely crucially on linearity. In a related model but with fewer restrictions on strategies, he finds that some pooling is desirable (see also Kihlstrom and Postlewaite 1983).

One objection to these models is that it is difficult to see how the large trader can commit himself to a pricing strategy beforehand. To begin with, in many circumstances there is no "beforehand." Often, a trader is in the market only because he has acquired private information. Before obtaining this information, he may not foresee his participation and so cannot contemplate what his strategy will be. But even if there is a well-defined ex ante period, the trader will generally 
wish, once he acquires his information, to charge a price different from the one prescribed by his Stackelberg strategy. ${ }^{1}$

Another shortcoming of some of the papers is the restriction to linearity. The principal justification offered for looking only at linear strategies seems to be analytic convenience.

Kyle (1985) overcomes the first drawback (although not the second). He constructs a dynamic model in which a large insider faces irrational players and risk-neutral market makers. Rather than assume that the insider can precommit to a strategy, he supposes that, at all dates, the insider's behavior is optimal given the strategies and beliefs of the others; that is, he studies perfect Bayesian equilibrium (PBE). One interesting feature of the equilibrium examined is that the insider trades in such a way that his private information is incorporated by prices only gradually. However, Kyle derives only the equilibrium in which traders use linear strategies (see also Altug 1985).

As we explain in Section IV, models such as Kyle's and ours tend to exhibit many PBEs. Thus some restriction is necessary if any predictions are to be made. However, simply imposing linearity seems quite arbitrary. Our approach is to suppose that, by virtue of his market power, the large trader should be able to influence not only the market price but also traders' beliefs. We maintain, therefore, that a natural PBE on which to focus is the one most favored by the large trader. We study this equilibrium without imposing any a priori restriction on strategies.

In Section II, we lay out a model of an asset market with a large "inside" trader and many small outsiders. The large trader is an insider by virtue of having private information about the mean of the asset's return. In Section III, we define perfect Bayesian equilibrium and show that PBEs satisfy two monotonicity properties (proposition 1). Section IV demonstrates that a completely separating equilibrium always exists in our model (proposition 2) and that a completely pooling equilibrium also exists (proposition 3) provided that the information parameter $\tilde{\theta}$ does not vary too much (proposition 4 shows what can go wrong with excessive variability). There is also a continuum of intermediate equilibria. However, proposition 5 establishes that the large trader's favorite equilibrium will always involve complete pooling or complete separation. In Section $\mathrm{V}$, we formalize the intuitive

\footnotetext{
${ }^{1}$ One possible justification for the Stackelberg equilibrium is concern for reputation, if the large trader transacts on this market repeatedly. But as we explain in Laffont and Maskin (1987), such a reputation effect relies on quite sophisticated behavior on the part of small traders.
} 
argument above and demonstrate in proposition 6 that pooling is optimal for the large trader provided that $\tilde{\theta}$ does not vary too much. (Drawing on propositions 4 and 5, proposition 7 establishes the optimality of separating equilibrium for a highly variable $\tilde{\theta}$.) Through Section $\mathrm{V}$, we concentrate on the case in which $\tilde{\theta}$ reflects information about the asset's mean return. In Section VI, we briefly argue that our results carry through when $\tilde{\theta}$ measures the variability of the return (proposition 8). We examine the welfare of the small traders in Section VII, where we establish that they too prefer pooling to separating equilibria (proposition 9) when $\tilde{\theta}$ does not vary too much. Finally, we offer a few concluding comments in Section VIII. The Appendix provides the proofs of propositions $2-5$ and 9.

\section{The Model}

We consider a two-period model with two assets: a safe asset (money) with (gross) return normalized to one and a risky asset with return $\tilde{\theta}$ $+\tilde{\epsilon}$, where $\tilde{\epsilon}$ is a zero-mean random variable with cumulative distribution function $F$ and $\tilde{\theta}$ is a random variable, independent of $\tilde{\boldsymbol{\epsilon}}$, that takes on the values $\theta_{1}$ and $\theta_{2}\left(\theta_{1}<\theta_{2}\right)$ with probabilities $\pi_{1}$ and $\pi_{2}$. Assets are traded in period 1 and $\tilde{\epsilon}$ is realized in period 2. The variable $\tilde{\theta}$ is realized in the first period (before trade), but its value is not known to all traders.

There is a continuum of identical risk-averse traders of Lebesgue measure one who initially own all the risky asset but do not know the realization of $\tilde{\theta}$ in the first period. In period 1, the endowment of the typical small trader comprises $w_{0}$ units of money and one unit of risky asset. His budget constraint in period 2 is therefore

$$
\alpha v+b=w_{0}+v,
$$

where money is the numeraire, $v$ is the price of the risky asset, $b$ is the final money holding, and $\alpha$ is the share of the risky assets that he keeps. His income in period 2 is therefore $b+\alpha(\tilde{\theta}+\tilde{\epsilon})$ or, from (1),

$$
w_{0}+v+\alpha(\tilde{\boldsymbol{\theta}}+\tilde{\boldsymbol{\epsilon}}-v) .
$$

If $u(\cdot)\left(u^{\prime}>0, u^{\prime \prime}<0\right)$ is the small trader's von NeumannMorgenstern utility function for second-period income, his expected utility in period 1 is

$$
\begin{gathered}
\pi_{1} E u\left(w_{0}+v+\alpha\left(\theta_{1}+\tilde{\epsilon}-v\right)\right)+\pi_{2} E u\left(w_{0}+v+\alpha\left(\theta_{2}+\tilde{\epsilon}-v\right)\right) \\
\text { or, if we set } U(\theta, \alpha, v)=E u\left(w_{0}+v+\alpha(\theta+\tilde{\epsilon}-v)\right), \\
\pi_{1} U\left(\theta_{1}, \alpha, v\right)+\pi_{2} U\left(\theta_{2}, \alpha, v\right) .
\end{gathered}
$$

We shall assume that $u$ exhibits nonincreasing absolute risk aversion. 
In our model, there is also a risk-neutral large trader who has a period 1 endowment of one unit of money and zero units of the risky asset. Unlike the small traders, he knows the realization of $\tilde{\theta}$. If $\tilde{\theta}=\theta$ and he buys a share $\beta$ of the risky asset, his expected payoff in period 1 is $1+\beta(\theta-v)$.

After learning $\theta$, the large trader chooses a quantity to buy. Price adjusts to equate supply and demand, that is, $\beta=1-\alpha$. Equivalently, we can assume (and this is the approach we take here) that he chooses a price $v$, and so the small traders determine the quantity exchanged. In period 2 the realizations of $\tilde{\theta}$ and $\tilde{\epsilon}$ become public knowledge.

A large-trader strategy is a mapping $v:\left\{\theta_{1}, \theta_{2}\right\} \rightarrow \mathbb{R}$ that prescribes a price $v(\theta)$ on the basis of the trader's private information $\theta$. In principle, $v(\cdot)$ can be a random function. We show in proposition 5 , however, that randomness is never optimal for the large trader.

A small-trader strategy is a mapping $\alpha: \mathbb{R} \rightarrow[0,1]$ that represents the share of the risky asset retained for each price. Given the strict concavity of $u$, the optimal $\alpha$ given $v$ will always be unique.

Conditional beliefs for the typical small trader are represented by a mapping that associates to each price $v$ a probability function $g(\cdot \mid v)$ on $\left\{\theta_{1}, \theta_{2}\right\}$, where $g(\theta \mid v)$ is the probability that the small trader attaches to the value $\theta$ given price $v$.

\section{Perfect Bayesian Equilibrium}

A perfect Bayesian equilibrium for our model is a pair of strategies $(v(\cdot)$, $\alpha(\cdot))$ and a family of conditional beliefs $g(\cdot \mid \cdot)$ such that (i) for all $v$ in the range of $v(\cdot), g(\cdot \mid v)$ is the conditional probability of $\tilde{\theta}$ obtained by updating the prior $\left(\pi_{1}, \pi_{2}\right)$, using $v(\cdot)$, in Bayesian fashion; (ii) for all $v, \alpha(v) \in \operatorname{argmax}_{\alpha} \Sigma_{\imath=1}^{2} U\left(\theta_{\imath}, \alpha, v\right) g\left(\theta_{\imath} \mid v\right)$; and (iii) for all $\theta, v(\theta) \in$ $\operatorname{argmax}_{v}[1-\alpha(v)](\theta-v)$.

Condition i stipulates that small traders have rational expectations. Conditions ii and iii are simply the requirements that traders be optimizing. Condition iii implies that

$$
\begin{gathered}
{[1-\alpha(v(\theta))][\theta-v(\theta)]} \\
\geq\left[1-\alpha\left(v\left(\theta^{\prime}\right)\right)\right]\left[\theta-v\left(\theta^{\prime}\right)\right] \text { for any } \theta, \theta^{\prime} .
\end{gathered}
$$

Perfect Bayesian equilibria satisfy the following two standard monotonicity properties.

Proposition 1. In any PBE, $\alpha(\cdot)$ is nonincreasing on the set of prices that are charged in equilibrium and $v(\cdot)$ is nondecreasing.

Proof. Formula (2) can be rewritten as

$$
\left(1-\alpha_{1}\right)\left(\theta_{1}-v_{1}\right) \geq\left(1-\alpha_{2}\right)\left(\theta_{1}-v_{2}\right),
$$




$$
\left(1-\alpha_{2}\right)\left(\theta_{2}-v_{2}\right) \geq\left(1-\alpha_{1}\right)\left(\theta_{2}-v_{1}\right),
$$

where $v_{\imath}$ is in the range of $v\left(\theta_{\imath}\right)$ and $\alpha_{\imath}=\alpha\left(v_{\imath}\right)$ for $i=1$, 2. Adding (3a) and $(3 \mathrm{~b})$ yields

$$
\left(\alpha_{1}-\alpha_{2}\right)\left(\theta_{2}-\theta_{1}\right) \geq 0 \text {. }
$$

Therefore,

$$
\alpha_{1} \geq \alpha_{2}
$$

Now suppose, contrary to the proposition, that $v_{1}>v_{2}$. In view of (4),

$$
\left(1-\alpha_{1}\right)\left(\theta_{1}-v_{1}\right)<\left(1-\alpha_{2}\right)\left(\theta_{1}-v_{2}\right),
$$

contradicting (3a). Hence $v(\cdot)$ is nondecreasing and, from $(4), \alpha(\cdot)$ is nonincreasing, as required. Q.E.D.

In common with other signaling models, there is, in general, a considerable multiplicity of equilibria in our framework. To help characterize these equilibria, we first define $\hat{\alpha}(v, \theta)$ to be the fraction of the asset retained by small traders if price is $v$ and they know that $\tilde{\theta}$ $=\theta$. Similarly, let $\alpha^{0}\left(v, \theta_{1}, \theta_{2}\right)$ be the fraction retained if the probability that $\tilde{\theta}=\theta_{i}$ is $\pi_{i}$. Note that $\hat{\alpha}$ and $\alpha^{0}$ are well defined because of the concavity of the small traders' utility function. We first show that they are increasing in $\theta$. To obtain this result, we shall invoke our assumption of nonincreasing absolute risk aversion on the part of the small traders. Moreover, we shall assume an interior solution to the small traders' problem.

Lemma. $\hat{\alpha}_{2}(v, \theta)>0$ and $\alpha_{2}^{0}\left(v, \theta_{1}, \theta_{2}\right)>0$, where subscripts denote partial derivatives.

Proof. $\hat{\alpha}(v, \theta)$ solves

$$
\max _{\alpha} E u\left(w_{0}+v+\alpha(\theta+\tilde{\epsilon}-v)\right) .
$$

Hence, the first-order condition is

$$
E(\boldsymbol{\theta}+\tilde{\boldsymbol{\epsilon}}-v) u^{\prime}\left(w_{0}+v+\hat{\alpha}(v, \theta)(\theta+\tilde{\boldsymbol{\epsilon}}-v)\right)=0 .
$$

Differentiating (5) with respect to $\theta$, we obtain

$$
\hat{\alpha}_{2}=\frac{-E\left[u^{\prime}+\hat{\alpha}(\theta+\tilde{\epsilon}-v) u^{\prime \prime}\right]}{E(\theta-\tilde{\epsilon}+v)^{2} u^{\prime \prime}} .
$$

The denominator of the right-hand side of (6) is negative because $u^{\prime \prime}$ $<0$. Because of nonincreasing absolute risk aversion, $E(\theta+\tilde{\epsilon}-v) u^{\prime \prime}$ $\geq 0$ (see Arrow 1971), and so the numerator is negative as well. Hence, with nonincreasing absolute risk aversion, $\hat{\alpha}_{2}(v, \theta)>0$. The argument is similar for $\alpha_{2}^{0}\left(v, \theta_{1}, \theta_{2}\right)$. Q.E.D. 


\section{Separating and Pooling Equilibria}

Using the lemma, we shall show that there always exists a completely separating equilibrium in our model. First define $v^{*}(\theta)$ to be the solution of the program

$$
\max _{v}(\theta-v)[1-\hat{\alpha}(v, \theta)] .
$$

For convenience, we shall assume throughout that the solution to (7) is unique for all $\theta$, so that $v^{*}(\theta)$ is well defined. Take

$$
\alpha^{*}(\theta)=\hat{\alpha}\left(v^{*}(\theta), \theta\right) .
$$

The pair $\left(v^{*}(\theta), \alpha^{*}(\theta)\right)$ are the equilibrium price and quantity that would obtain if the small traders had perfect information, that is, if they knew that $\tilde{\theta}=\theta$. Notice that

$$
-\left[\theta-v^{*}(\theta)\right] \hat{\alpha}_{1}\left(v^{*}(\theta), \theta\right)-\left[1-\hat{\alpha}\left(v^{*}(\theta), \theta\right)\right]=0,
$$

and so

$$
\hat{\alpha}_{1}\left(\nu^{*}(\theta), \theta\right)<0 .
$$

Proposition 2. There exists a PBE $(v(\cdot), \alpha(\cdot), g(\cdot \mid \cdot))$ in which $v\left(\theta_{1}\right)<$ $v\left(\theta_{2}\right)$. Moreover, in this equilibrium, $\left(v\left(\theta_{2}\right), \alpha\left(\theta_{2}\right)\right)=\left(v^{*}\left(\theta_{2}\right), \alpha^{*}\left(\theta_{2}\right)\right)$, and $v(\cdot)$ is a solution to the following program:

$$
\max _{v_{1}, v_{2}} \sum_{i} w_{i}\left(\theta_{i}-v_{\imath}\right)\left[1-\hat{\alpha}\left(v_{i}, \theta_{\imath}\right)\right]
$$

subject to

$$
\left(\theta_{2}-v_{2}\right)\left[1-\hat{\alpha}\left(v_{2}, \theta_{2}\right)\right] \geq\left(\theta_{2}-v_{1}\right)\left[1-\hat{\alpha}\left(v_{1}, \theta_{1}\right)\right]
$$

for any positive weights $w_{1}$ and $w_{2}$.

We relegate the formal proof of proposition 2 to the Appendix, but we can readily describe the construction of equilibrium. We take $v\left(\theta_{2}\right)$ $=v^{*}\left(\theta_{2}\right)$ and let $v\left(\theta_{1}\right)$ be a $v_{1}$ that solves (7) subject to (10). Because these choices of $v\left(\theta_{1}\right)$ and $v\left(\dot{\theta}_{2}\right)$ are independent of $w_{1}$ and $w_{2}$, they solve program (9)-(10) for any choice of weights. To complete the description of equilibrium, we take $\alpha\left(v_{\imath}\right)=\hat{\alpha}\left(v_{\imath}, \theta_{\imath}\right)$, for $i=1,2$; $\alpha(v)$ $=\hat{\alpha}\left(v, \theta_{2}\right)$, for $v \notin\left\{v_{1}, v_{2}\right\} ; g\left(\theta_{i} \mid v_{i}\right)=1$, for $i=1,2$; and $g\left(\theta_{2} \mid v\right)=1$, for $v \notin\left\{v_{1}, v_{2}\right\}$.

Notice that when $\tilde{\theta}=\theta_{2}$, the large trader is unconstrained by the informational imperfection: the price and allocation are the same as though the small traders could directly observe $\tilde{\theta}$. When $\tilde{\theta}=\theta_{1}$, however, $v$ and $\alpha$ are restricted by the incentive constraint (10).

The beliefs $g(\cdot \mid v)$ that we invoke in the proof of proposition 2 are extreme and discontinuous: for $v=v\left(\theta_{1}\right)$, the small traders believe that $\tilde{\theta}=\theta_{1}$, but for an only slightly different price they believe that $\tilde{\theta}$ 


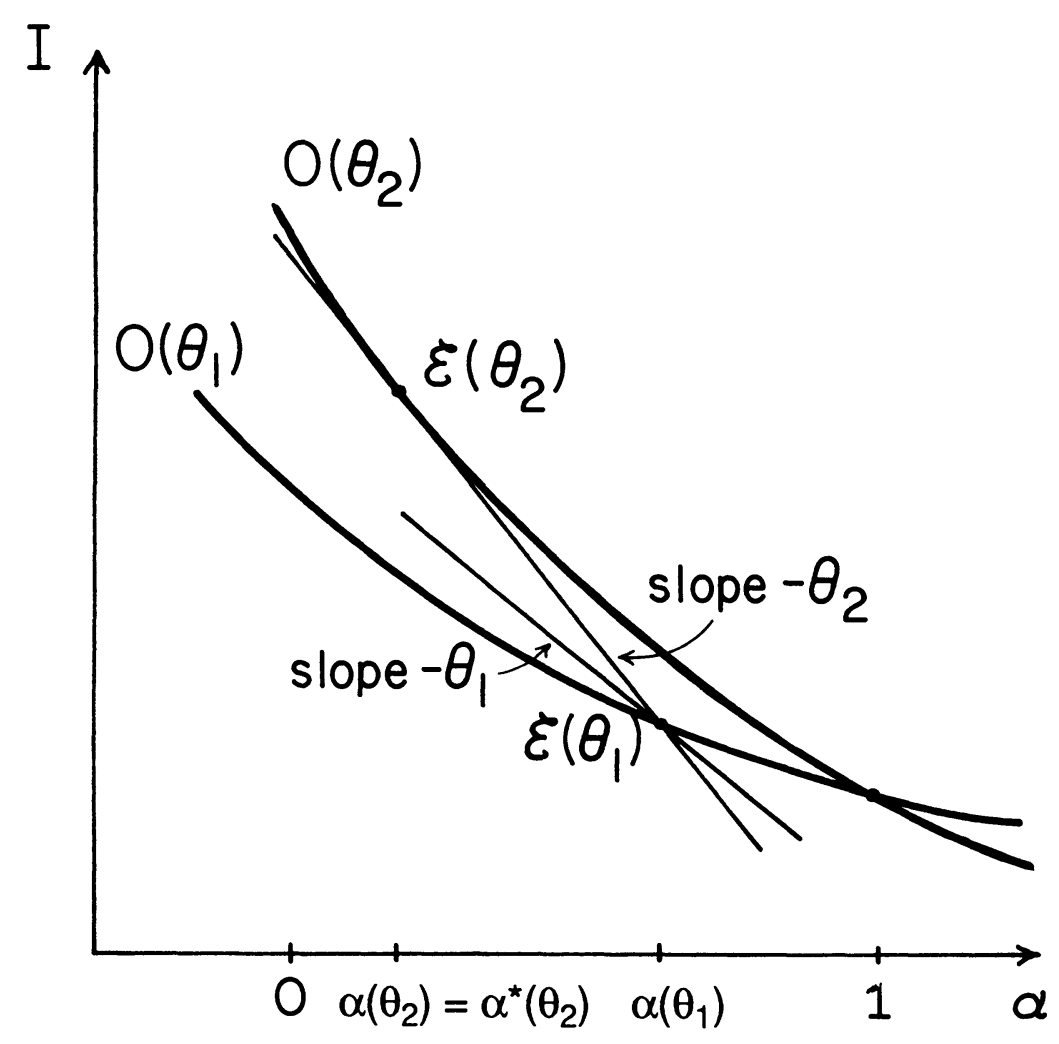

FIG. 1

$=\theta_{2}$. Using the methods of Laffont and Maskin (1987), however, we could devise alternative beliefs that are continuous and monotonic in $v$.

Figure 1 illustrates the separating equilibrium of proposition 2 in $\alpha$ $I$ space, where $I$ is the amount of a small trader's wealth invested in the safe asset: $I=w_{0}+v(1-a) \cdot{ }^{2}$ The curve $O(\theta)$ is a small trader's offer curve when he believes that $\tilde{\theta}=\theta$. It is obtained by maximizing expected utility $E u(I+\alpha(\theta+\tilde{\epsilon}))$ subject to the budget constraint $I+$ $v(\theta) \alpha=w_{0}+v(\theta)$. The large trader maximizes his linear objective function $\theta(1-\alpha)-I$ (whose indifference curves have slope $-\theta$ if $\tilde{\theta}$ $=\theta$ ) over the offer curve (subject to the incentive constraint [10]). Denote the solution by $\mathscr{E}(\theta)$. Then $\mathscr{E}(\theta)$ is the equilibrium allocation when $\tilde{\theta}=\theta$. As we noted above, $\mathscr{E}\left(\theta_{2}\right)$ is constrained only by the offer curve $O\left(\theta_{2}\right)$, where $\mathscr{E}\left(\theta_{1}\right)$ not only must lie on $O\left(\theta_{1}\right)$ but must satisfy the

\footnotetext{
${ }^{2}$ We thank a referee for suggesting this graphical illustration.
} 


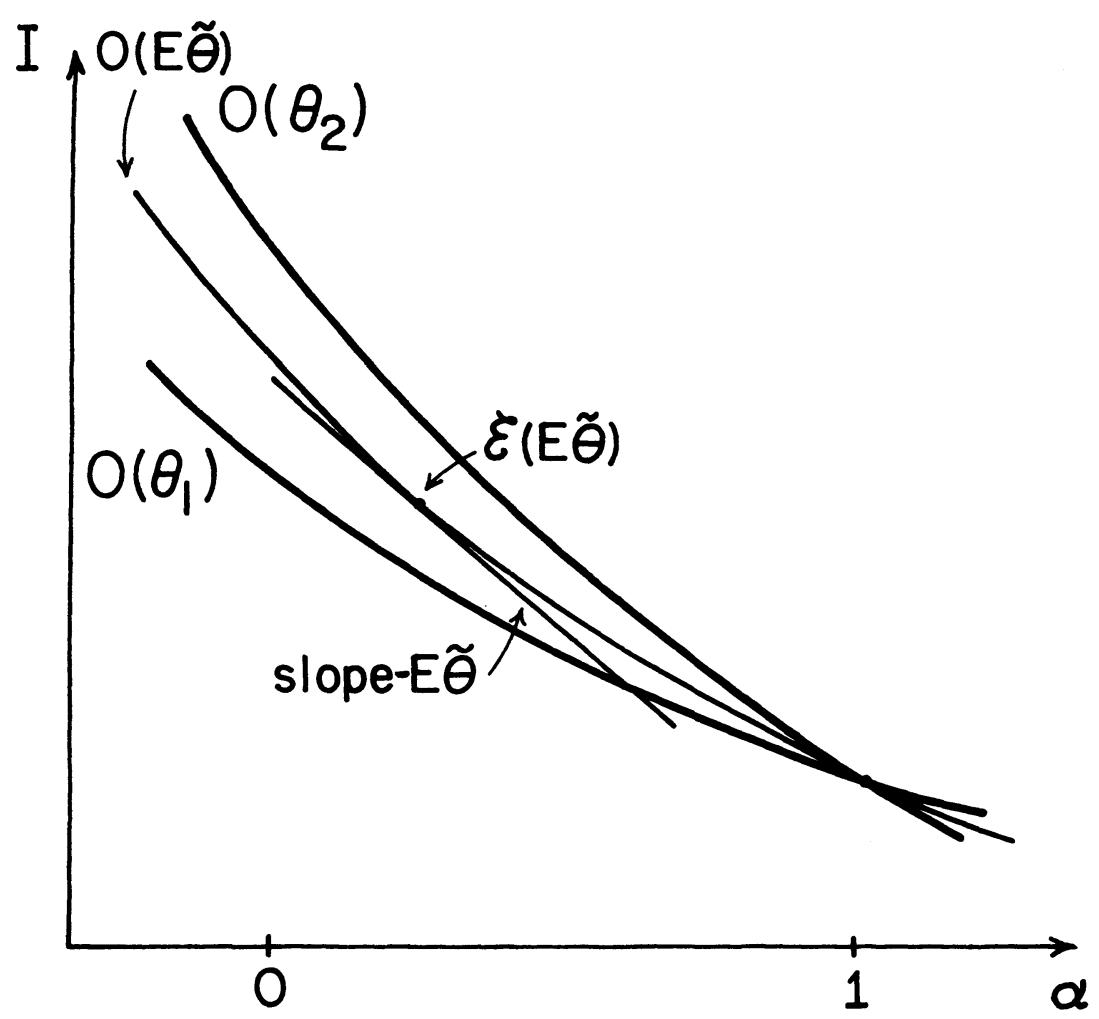

FIG. 2

restriction that if $\tilde{\theta}=\theta_{2}$, the large trader does not prefer $\mathscr{E}\left(\theta_{1}\right)$ to $\mathscr{E}\left(\theta_{2}\right)$.

We next demonstrate that, at the opposite end of the spectrum, a pooling equilibrium always exists when $\theta_{1}$ is not too far from $\theta_{2}$.

Proposition 3. For $\theta_{1}$ sufficiently near $\theta_{2}$, there exists a PBE $(v(\cdot)$, $\alpha(\cdot), g(\cdot \mid \cdot))$ in which $v\left(\theta_{1}\right)=v\left(\theta_{2}\right)=v^{0}\left(\theta_{1}, \theta_{2}\right)$, where $v=v^{0}\left(\theta_{1}, \theta_{2}\right)$ solves the program

$$
\max _{v} \sum_{i} \pi_{i}\left(\theta_{i}-v\right)\left[1-\alpha^{0}\left(v, \theta_{1}, \theta_{2}\right)\right] .
$$

Proof. See the Appendix.

The pooling equilibrium of proposition 3 is illustrated in figure 2 . The small traders' offer curve $O(E \tilde{\theta})$ is obtained by maximizing $\pi_{1} E u\left(I+\alpha\left(\theta_{1}+\tilde{\epsilon}\right)\right)+\pi_{2} E u\left(I+\alpha\left(\theta_{2}+\tilde{\epsilon}\right)\right)$ subject to the budget constraint $I+v(\theta) \alpha=w_{0}+v(\theta)$. The equilibrium allocation $\mathscr{E}(E \tilde{\theta})$ is obtained by choosing the allocation on $O(E \tilde{\theta})$ that maximizes the large trader's expected utility (his indifference curves have slope $-E \tilde{\theta}$ ). 
The requirement in proposition 3 that $\theta_{1}$ and $\theta_{2}$ not be too far apart is needed to ensure that the large trader has no incentive to set $v \neq$ $v^{0}\left(\theta_{1}, \theta_{2}\right)$. To see that this constraint can be a problem, we next note that a pooling equilibrium may fail to exist if $\theta_{2}$ is too big relative to $\theta_{1}$.

Proposition 4. Suppose that $\lim _{x \rightarrow \infty} x u^{\prime}(x)=\infty$ and $\alpha^{*}(\theta)<1$ for all $\theta$. Given $\theta_{1}$, there exists $\bar{\theta}_{2}$ such that there is no pooling equilibrium for $\theta_{2}>\bar{\theta}_{2}$.

If the large trader is willing to buy when $\tilde{\theta}=\theta_{1}$, then an equilibrium pooling price $v$ must satisfy $v \leq \theta_{1}$. But given such a low price, the small traders will refuse to sell if $\theta_{2}$ is big enough. Thus for such $\theta_{2}$, the large trader buys nothing in a pooling equilibrium. But because $\alpha^{*}\left(\theta_{2}\right)<1$, the large trader can obtain a positive payoff by setting price $v^{*}\left(\theta_{2}\right)$, a contradiction. The formal proof can be found in the Appendix.

\section{The Large Trader's Favorite Equilibrium}

When a pooling equilibrium exists, there is also a continuum of "semiseparating" equilibria (where either $v\left(\theta_{1}\right)$ or $v\left(\theta_{2}\right)$ is a random variable) intermediate between complete pooling and complete separating (there are also pooling and separating equilibria other than the ones we constructed in propositions 2 and 3). We argued in the Introduction, however, that by virtue of his market power, the large trader ought to be able to influence other traders' beliefs and so ensure a favorable equilibrium for himself.

The simplest way that he can accomplish this is, before learning the value of $\theta$, to make a public announcement that he will play his favorite equilibrium. If the small traders believe him, they can do no better than play their corresponding equilibrium strategies. Moreover, it makes sense for them to believe him since, if they do, he has no incentive to deviate.

Of course, such a public pronouncement may be implausible or impossible. In Laffont and Maskin (1987), we consider another way of formalizing the large trader's influence over beliefs. Suppose that the market is repeated many times (where $\theta$ is drawn independently each time), that small traders have prior beliefs about the statistical relationship between $\theta$ and $v$, and that they update these beliefs on the basis of their previous experience (under the hypothesis that the joint distribution between $\theta$ and $v$ is stationary). Suppose that the large trader's discount rate is near zero (which is equivalent to supposing that he transacts frequently). If he chooses prices over time to maximize his expected discounted sum of payoffs and if, as a result, buyers' beliefs converge over time, behavior ultimately closely approximates that in the PBE (of the one-shot model) that maximizes 
the large trader's ex ante expected payoff $\Sigma_{i=1}^{2} \pi_{i}\left(\theta_{i}-v_{i}\right)\left(1-\alpha_{i}\right)$. (In Laffont and Maskin [1987], we also examine a more game-theoretic foundation for this equilibrium.)

A quite different justification for focusing on the large trader's favorite PBE derives from the welfare analysis in Section VII below. It turns out that provided that $\tilde{\theta}$ does not vary too much, the pooling equilibrium of proposition 3 not only is the large trader's favorite $\mathrm{PBE}$, but is preferred by the small traders to any separating equilibrium. Thus Pareto dominance favors pooling.

Henceforth, we shall simply assume that the large trader is able to attain his ex ante best PBE (BPBE) and shall study the properties of this equilibrium. We first observe that we may as well assume that the $\mathrm{BPBE}$ is deterministic (i.e., either a pure separating or a pure pooling equilibrium).

Proposition 5. There exists a BPBE $(v(\cdot), \alpha(\cdot), g(\cdot \mid \cdot))$ in which $v(\cdot)$ is deterministic.

If $(v(\cdot), \alpha(\cdot), g(\cdot \mid \cdot))$ is a BPBE in which $v\left(\theta_{1}\right)$ and $v\left(\theta_{2}\right)$ are random, choose $v_{i} \in$ support of $v\left(\theta_{i}\right), i=1,2$, so that $v_{1}<\max$ \{support of $\left.v\left(\theta_{1}\right)\right\} \leq \min \left\{\right.$ support of $\left.v\left(\theta_{2}\right)\right\}<v_{2}$. Then we can construct an alternative PBE $(\bar{v}(\cdot), \bar{\alpha}(\cdot), \bar{g}(\cdot \mid \cdot))$ in which $\bar{v}\left(\theta_{i}\right)=v_{i}, i=1,2$. (The large trader's incentive constraints will be satisfied since they hold for the original PBE.) Clearly, the large trader's payoff, for each value of $\theta_{i}$, is the same as before, and so the new PBE is a deterministic BPBE. For the details and the other cases (where one of $v\left(\theta_{1}\right)$ and $v\left(\theta_{2}\right)$ is not random), see the Appendix.

We next turn to our main result: the observation that the large trader profits from concealing his information if $\theta_{1}$ and $\theta_{2}$ are not too far apart.

Proposition 6. If $\theta_{1}$ and $\theta_{2}$ are sufficiently close, the BPBE is the pooling equilibrium that solves program (11).

Proof. From proposition 3, program (11) defines a pooling equilibrium that exists for $\theta_{1}$ near enough $\theta_{2}$, and, by virtue of proposition 5 , we need compare it only with the large trader's favorite separating equilibrium. From proposition 2, this latter equilibrium solves the program

$$
\max _{\left(v_{1}, v_{2}\right)} \sum_{i} \pi_{i}\left(\theta_{i}-v_{i}\right)\left[1-\hat{\alpha}\left(v_{i}, \theta_{i}\right)\right]
$$

subject to

$$
\left(\theta_{2}-v_{2}\right)\left[1-\hat{\alpha}\left(v_{2}, \theta_{2}\right)\right] \geq\left(\theta_{2}-v_{1}\right)\left[1-\hat{\alpha}\left(v_{1}, \theta_{1}\right)\right] .
$$

Clearly, the solution $\left(v\left(\theta_{1}\right), v\left(\theta_{2}\right)\right)$ to the program (12)-(13) satisfies $v\left(\theta_{2}\right)=v^{*}\left(\theta_{2}\right)$. We first show that, for $\theta_{1}$ near $\theta_{2}$ (but $\left.\theta_{1} \neq \theta_{2}\right), v\left(\theta_{1}\right) \neq$ 
$v^{*}\left(\theta_{1}\right)$. Applying the envelope theorem, we have

$$
\begin{aligned}
\frac{d}{d \theta_{1}} & {\left.\left[\theta_{2}-v^{*}\left(\theta_{1}\right)\right]\left[1-\hat{\alpha}\left(v^{*}\left(\theta_{1}\right), \theta_{1}\right)\right]\right|_{\theta_{1}=\theta_{2}} } \\
& =-\left[\theta_{1}-v^{*}\left(\theta_{1}\right)\right] \hat{\alpha}_{2}\left(v^{*}\left(\theta_{1}\right), \theta_{1}\right),
\end{aligned}
$$

which is negative because $\hat{\alpha}_{2}>0$. Thus if $v\left(\theta_{1}\right)=v^{*}\left(\theta_{1}\right),(13)$ is contradicted. Thus $v\left(\theta_{1}\right) \neq v^{*}\left(\theta_{1}\right)$, as claimed.

Now for $\theta_{1}$ near $\theta_{2}, v_{1}=v^{*}\left(\theta_{1}\right)$ violates (13) but $v\left(\theta_{1}\right)$ is near $v^{*}\left(\theta_{1}\right)$. Hence, $v\left(\theta_{1}\right)$ must satisfy (13) with equality. But (13) is violated for all $v_{1}$ between $v^{*}\left(\theta_{1}\right)$ and $v^{*}\left(\theta_{2}\right)$, and, from proposition $1, v\left(\theta_{1}\right) \leq v^{*}\left(\theta_{2}\right)$. Hence $v\left(\theta_{1}\right)$ is the largest price less than $v^{*}\left(\theta_{1}\right)$ such that (13) holds with equality.

The derivative of the large trader's payoff in the separating equilibrium with respect to $\theta_{1}$ is

$$
\begin{aligned}
& \frac{d}{d \theta_{1}} \sum_{\imath} \pi_{i}\left[\theta_{\imath}-v\left(\theta_{\imath}\right)\right]\left[1-\hat{\alpha}\left(v\left(\theta_{\imath}\right), \theta_{\imath}\right)\right] \\
& =\pi_{1} \frac{d}{d \theta_{1}}\left[\theta_{1}-v\left(\theta_{1}\right)\right]\left[1-\hat{\alpha}\left(v\left(\theta_{1}\right), \theta_{1}\right)\right] .
\end{aligned}
$$

The right-hand side of (14) can be rewritten as

$$
\pi_{1}\left(1-\hat{\alpha}\left(v\left(\theta_{1}\right), \theta_{1}\right)-\left\{\left[\theta_{1}-v\left(\theta_{1}\right)\right] \frac{d \hat{\alpha}}{d \theta_{1}}+(1-\hat{\alpha}) \frac{d v\left(\theta_{1}\right)}{d \theta_{1}}\right\}\right) .
$$

Because (13) is binding,

$$
\frac{d}{d \theta_{1}}\left[\theta_{2}-v\left(\theta_{1}\right)\right]\left[1-\hat{\alpha}\left(v\left(\theta_{1}\right), \theta_{1}\right)\right]=0 .
$$

Hence

$$
\left[\theta_{2}-v\left(\theta_{1}\right)\right] \frac{d \hat{\alpha}}{d \theta_{1}}+(1-\hat{\alpha}) \frac{d v\left(\theta_{1}\right)}{d \theta_{1}}=0 .
$$

But at $\theta_{1}=\theta_{2}$, the left-hand side of (17) and the expression in braces in (15) are the same. Therefore, from (14), (15), and (17),

$$
\begin{gathered}
\frac{d}{d \theta_{1}} \sum_{i} \pi_{i}\left[\theta_{i}-v\left(\theta_{i}\right)\right]\left[1-\hat{\alpha}\left(v\left(\theta_{i}\right), \theta_{i}\right)\right] \\
=\pi_{1}\left[1-\hat{\alpha}\left(v\left(\theta_{1}\right), \theta_{1}\right)\right] .
\end{gathered}
$$

Applying the envelope theorem to the solution $v^{0}\left(\theta_{1}, \theta_{2}\right)$ to program (11), we find that the derivative of the large trader's payoff with 
respect to $\theta_{1}$ is

$$
\begin{aligned}
\frac{d}{d \theta_{1}} \sum_{i} \pi_{i}\left[\theta_{i}-v^{0}\left(\theta_{1}, \theta_{2}\right)\right] & {\left[1-\alpha^{0}\left(v^{0}\left(\theta_{1}, \theta_{2}\right), \theta_{1}, \theta_{2}\right)\right] } \\
=\pi_{1}\left[1-\alpha^{0}\left(v^{0}\left(\theta_{1}, \theta_{2}\right), \theta_{1}, \theta_{2}\right)\right] & \\
& \quad-\sum_{i} \pi_{i}\left[\theta_{i}-v^{0}\left(\theta_{1}, \theta_{2}\right)\right] \alpha_{2}^{0}\left(v^{0}\left(\theta_{1}, \theta_{2}\right), \theta_{1}, \theta_{2}\right) .
\end{aligned}
$$

But because $\alpha_{2}^{0}>0$, the right-hand side of (19) is less than that of (18). Hence, because the pooling and separating equilibria generate the same payoffs when $\theta_{1}=\theta_{2}$, the former yields the large trader the higher payoff for $\theta_{1}$ near (but strictly less than) $\theta_{2}$. Q.E.D.

We provided a rough heuristic explanation for proposition 6 in the Introduction. Let us give a somewhat more rigorous but still intuitive account to supplement the formal proof. To see that the "downward" incentive constraint (13) must be binding in a separating equilibrium when $\theta_{1}$ is near $\theta_{2}$, suppose that it is not. Then for $i=1,2, v\left(\theta_{i}\right)=$ $v^{*}\left(\theta_{i}\right)$; that is, equilibrium prices are the same as they would be if the small traders knew the realization of $\tilde{\theta}$. Now if $\tilde{\theta}=\theta_{2}$, the effect on the large trader's payoff of setting $v=v^{*}\left(\theta_{1}\right)$ rather than $v=v^{*}\left(\theta_{2}\right)$ is zero to the first order because the latter price maximizes $\left(\theta_{2}-v\right)[1-$ $\left.\hat{\alpha}\left(v, \theta_{2}\right)\right]$ and $v^{*}\left(\theta_{1}\right)$ is near $v^{*}\left(\theta_{2}\right)$. However, there is also an indirect effect that arises because $\hat{\alpha}\left(v, \theta_{1}\right)<\hat{\alpha}\left(v, \theta_{2}\right)$ : by setting $v^{*}\left(\theta_{1}\right)$, the large trader makes the others believe that $\tilde{\theta}=\theta_{1}$ and so lowers the proportion of the risky asset that they retain. Combining these two effects, we see that the large trader is better off setting $v=v^{*}\left(\theta_{1}\right)$ when $\tilde{\theta}=$ $\theta_{2}$, an impossibility. We thus conclude that (13) must be binding.

Now in the separating equilibrium $(v(\cdot), \alpha(\cdot), g(\cdot \mid \cdot))$, consider what happens to the large trader's expected payoff as the value $\theta_{1}$ increases. There are three effects: a direct increase at rate $\pi_{1}[1-$ $\left.\alpha\left(v\left(\theta_{1}\right), \theta_{1}\right)\right]$, an indirect decrease due to $-\alpha\left(v, \theta_{1}\right)$ falling (at rate $\left.-\alpha_{2}\left(v, \theta_{1}\right)\right)$, and another indirect increase due to $v\left(\theta_{1}\right)$ adjusting to keep (13) an equality: the closer $\theta_{1}$ is to $\theta_{2}$, the less $v\left(\theta_{1}\right)$ has to deviate from $v^{*}\left(\theta_{1}\right)$ in order to maintain (13), and so the greater is $\left(\theta_{1}-v_{1}\right)(1$ $-\alpha)$. In the pooling equilibrium, by contrast, the first two effects persist, but the third is not present since there is no incentive constraint corresponding to (13). Hence the rate of increase with $\theta_{1}$ of the large trader's payoff is slower in the pooling than in a separating equilibrium. Since payoffs from the two equilibria are the same when $\theta_{1}=\theta_{2}$, therefore, the pooling payoff must be higher when $\theta_{1}<\theta_{2}$.

The pooling and separating equilibria are compared in figure 3 . In the figure, the large trader's expected utility from the separating 


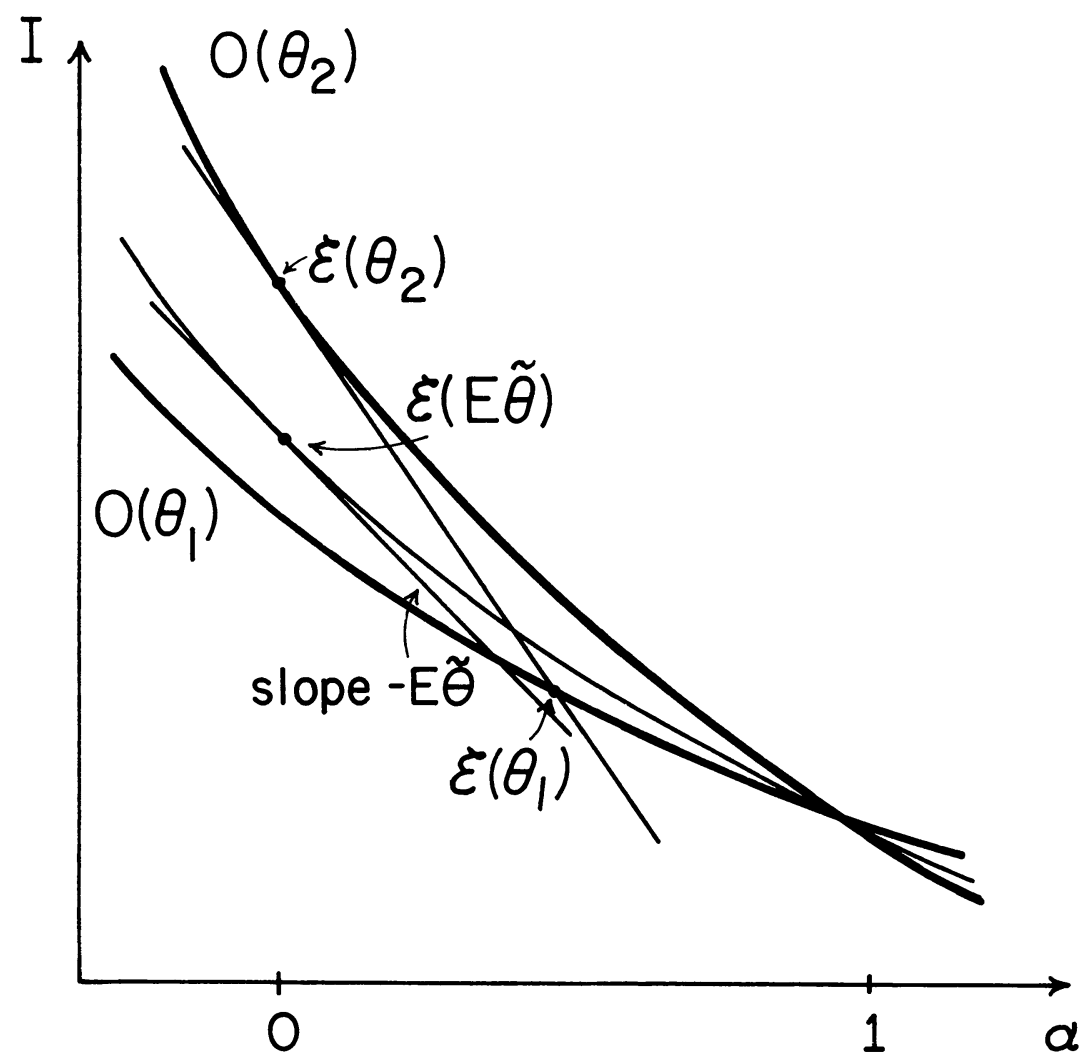

FIG. 3

equilibrium corresponds to $\mathscr{E}\left(\theta_{1}\right)$ because, whether $\tilde{\theta}=\theta_{1}$ or $\tilde{\theta}=\theta_{2}$, the allocation $\mathscr{E}\left(\theta_{1}\right)$ gives rise to maximal utility. Therefore, the pooling equilibrium dominates the separating equilibrium since the line with slope $-E \tilde{\theta}$ through $\mathscr{E}(E \tilde{\theta})$ is below that through $\mathscr{E}\left(\theta_{1}\right)$ (lower indifference curves denote higher utility). ${ }^{3}$

For $\theta_{2}$ big enough relative to $\theta_{1}$, a pooling equilibrium may fail to exist, as we noted in proposition 4 . In such a case, the seller's favorite $\mathrm{PBE}$ is separating.

Proposition 7. Suppose that $\lim _{x \rightarrow \infty} x u^{\prime}(x)=\infty$. For $\theta_{2}$ sufficiently big relative to $\theta_{1}$, the BPBE is the separating equilibrium defined by proposition 2.

Proof. From proposition 5, the BPBE is deterministic, that is, either completely separating or pooling. From proposition 4, a pooling equilibrium does not exist. Therefore, the BPBE must be the "best"

${ }^{3} \mathrm{~A}$ referee pointed out that, in general, a pooling equilibrium will dominate if $\pi_{1}$ is big enough, as fig. 3 makes clear. This observation complements proposition 6 . 
separating equilibrium, that is, the one defined by program (9)-(10) with $w_{i}=\pi_{i}{ }^{4}$ Q.E.D

\section{Private Information about Variability}

So far we have modeled the large trader's private information as knowledge about the mean return of the risky asset. For this section only, let us assume that the mean return is $\bar{\epsilon}$ and that private information parameter $\theta$ instead reflects the variability of the asset. Specifically, suppose that the distribution when $\tilde{\theta}=\theta_{1}$ is a mean-preserving spread (cf. Rothschild and Stiglitz 1970) of that when $\tilde{\theta}=\theta_{2}$. Then if $\hat{\alpha}(v, \theta)$ and $\alpha^{0}(v, \theta)$ are defined as in Section III, we conclude, by virtue of the small trader's risk aversion, that $\hat{\alpha}_{2}$ and $\alpha_{2}^{0}$ are positive.

In this setting, the large trader's payoff is

$$
(\bar{\epsilon}-v)(1-\alpha)
$$

independently of the realization of $\tilde{\theta}$. Recall that in the informal discussion following proposition 6 , there were three effects on the large trader's payoff from raising $\theta_{1}$ in a separating equilibrium: (i) the direct effect, (ii) the effect on $\alpha$, and (iii) the effect on $v$. We noted that in a pooling equilibrium, the third effect vanishes but $i$ and ii remain. When $\theta_{1}$ is replaced by $\bar{\epsilon}$ as in (20), effect $i$ vanishes in both the separating and pooling equilibria. But since we are subtracting the same effect from both equilibria, the large trader's payoff continues to increase faster in the separating equilibrium as a function of $\theta_{1}$. Thus he continues to favor the pooling equilibrium.

Proposition 8. In the variability model, the BPBE is a pooling equilibrium if $\theta_{1}$ and $\theta_{2}$ are sufficiently close.

Proof. Parallels that of proposition 6.

Just as proposition 6 continues to go through in the variability setting, so do propositions 2,3 , and 5 .

\section{Welfare}

We have concentrated until now on the large trader's welfare. Let us broaden our scope and consider the small traders' welfare as well.

It is sometimes asserted that insider trading is undesirable because insiders profit at the expense of small traders. Often implicit in such assertions, however, is the assumption not only that small traders are worse informed but that they are irrational. When traders have rational expectations, it is not at all clear that they can be "exploited" by insiders. Indeed, in our simple model, they clearly benefit from the

\footnotetext{
${ }^{4}$ Actually, however, the same solution results regardless of the weights $w_{i}$, as we remarked following proposition 2 .
} 
presence of the large trader. Were he prohibited from trading, they would be stuck holding all the risky asset themselves.

Moreover, although, as we have seen, the large trader may find it desirable to conceal his private information, this concealment need not work to the disadvantage of the small traders. As we shall show, the small traders prefer the pooling equilibrium of proposition 3 to any separating equilibrium provided that the variability of $\tilde{\theta}$ is not too great.

Proposition 9. If $\theta_{1}$ and $\theta_{2}$ are not too far apart, the small traders' ex ante utility is higher in the pooling equilibrium defined by program (17) than in any separating equilibrium.

As was true for the large trader (see the intuitive argument following proposition 6), the small traders' welfare differs to the first order between a pooling equilibrium and a separating equilibrium only because, in the latter, the price $v\left(\theta_{1}\right)$ must be chosen to satisfy the incentive constraint (13). But this constraint implies that $v\left(\theta_{1}\right)$ must be less than the "full information" level $v^{*}\left(\theta_{1}\right)$. Since lower prices hurt small traders, we conclude that they are worse off in the separating equilibrium. This argument is formalized in the Appendix.

Remark.-Although the traders are unanimous in preferring the pooling equilibrium of program (11) to any separating equilibrium, they do not agree on which pooling equilibrium is their favorite. The large trader, of course, likes the program (11) equilibrium best. The small traders, however, prefer the equilibrium with the highest possible price.

It is interesting to note that the effect on welfare of $\tilde{\theta}$ being private information is ambiguous, for both large and small traders. Formula (19) represents the derivative of the large trader's payoff with respect to $\theta_{1}$ when the value of $\tilde{\theta}$ is private information (provided that the variability of $\tilde{\theta}$ is not too great). One can readily show that the corresponding derivative when $\tilde{\theta}$ is common knowledge is exactly the same. Thus the large trader's payoff does not depend to the first order on whether or not $\tilde{\theta}$ is private information. Moreover, the second-order comparison depends on the second derivatives of $\alpha^{0}$ and $\hat{\alpha}$, which are not signable without additional assumptions on preferences. The analysis is similar for the small traders.

Thus our model exemplifies the principle that two market imperfections can be better than one. Introducing an informational asymmetry in the model may actually make all traders better off.

\section{Conclusion}

In competitive asset markets in which traders have rational expectations, prices are likely (with some qualifications) to reflect all relevant 
private information about the value of the asset. Indeed, if the large trader in the model of Section II were replaced by a continuum of price-taking, risk-neutral small traders with private information $\theta$, the market price $v(\theta)$ would just be $\theta$, and so would reveal all information.

We have argued, however, that in a model in which private information is possessed by a trader who is big enough to affect prices, the information efficiency of prices breaks down. Our model is very simple, but the intuition for why the large trader gains from concealing his information seems quite general. We believe, therefore, that the same sort of reasoning ought to apply to more elaborate market structures.

Our welfare conclusions are less likely to generalize. We noted in our model that, not only the large trader but the small trader too may prefer a pooling equilibrium to any separating equilibrium (proposition 9). This result, however, seems to depend on the small traders being on the opposite side of the market from the large trader. If there were also small traders buying the asset, then they would benefit from the fact that $v\left(\theta_{1}\right)$ must be comparatively low (see the discussion following proposition 9) in a separating equilibrium and so might prefer such an equilibrium.

\section{Appendix}

\section{Proof of Proposition 2}

In (10), set $v_{2}=v^{*}\left(\theta_{2}\right)$. Then $\hat{\alpha}\left(v_{2}, \theta_{2}\right)=\alpha^{*}\left(\theta_{2}\right)$. Clearly, $\hat{\alpha}\left(v, \theta_{1}\right)=1$ for $v$ low enough (possibly $-\infty$ ). Hence, there is a choice of $v_{1}$ for which (10) holds. From the lemma, $\hat{\alpha}\left(v^{*}\left(\theta_{2}\right), \theta_{1}\right)<\hat{\alpha}\left(v^{*}\left(\theta_{2}\right), \theta_{2}\right)=\alpha^{*}\left(\theta_{2}\right)$. Hence (10) is violated when $v_{1}=v^{*}\left(\theta_{2}\right)$. By continuity, there exists $v_{1}^{0}<v^{*}\left(\theta_{2}\right)$ such that (10) holds with equality when $v_{1}=v_{1}^{0}$. Thus from $(10), \alpha^{*}\left(\theta_{2}\right)<\hat{\alpha}\left(v_{1}^{0}, \theta_{1}\right)$, and so

$$
\left[\theta_{1}-v^{*}\left(\theta_{2}\right)\right]\left[1-\alpha^{*}\left(\theta_{2}\right)\right]<\left(\theta_{1}-v_{1}^{0}\right)\left[1-\hat{\alpha}\left(v_{1}^{0}, \theta_{1}\right)\right] .
$$

Consider the program

$$
\max _{v_{1}}\left(\theta_{1}-v_{1}\right)\left[1-\hat{\alpha}\left(v_{1}, \theta_{1}\right)\right]
$$

subject to

$$
\left[\theta_{2}-v^{*}\left(\theta_{2}\right)\right]\left[1-\alpha^{*}\left(\theta_{2}\right)\right] \geq\left(\theta_{2}-v_{1}\right)\left[1-\hat{\alpha}\left(v_{1}, \theta_{1}\right)\right] .
$$

From the argument above, constraint (A3) can be satisfied, and so a solution $v_{1}=v\left(\theta_{1}\right)$ exists. Define $v\left(\theta_{2}\right)=v^{*}\left(\theta_{2}\right)$ and $\alpha\left(v_{\imath}\right)=\hat{\alpha}\left(v\left(\theta_{\imath}\right), \theta_{\imath}\right), i=1,2$. Because $\left(v\left(\theta_{1}\right), \alpha\left(v\left(\theta_{1}\right)\right)\right)$ satisfies (A3), (3b) is satisfied, and in view of (A 1$)$ and the fact that $v\left(\theta_{1}\right)$ solves (A2)-(A3), (3a) is satisfied. Because $v\left(\theta_{2}\right)=v^{*}\left(\theta_{2}\right)$ and $v\left(\theta_{1}\right)$ solves $(\mathrm{A} 2)-(\mathrm{A} 3), v(\cdot)$ solves the program (9)-(10) for any positive weights $w_{1}$ and $w_{2}$. For rational expectations, we must take $g\left(\theta_{2} \mid v\left(\theta_{2}\right)\right)=1$ for $i$ $=1$, 2. For $v \neq v\left(\theta_{i}\right)$, let $g\left(\theta_{2} \mid v\right)=1$, and so $\alpha(v)=\hat{\alpha}\left(v, \theta_{2}\right)$. It remains to show that it does not pay the large trader to set $v \notin\left\{v\left(\theta_{1}\right), v\left(\theta_{2}\right)\right\}$. By definition of 
$v^{*}\left(\theta_{2}\right)$,

$$
\left[\theta_{2}-v\left(\theta_{2}\right)\right]\left[1-\alpha\left(v\left(\theta_{2}\right)\right)\right] \geq\left(\theta_{2}-v\right)\left[1-\hat{\alpha}\left(v, \theta_{2}\right)\right] \text { for all } v .
$$

Hence, we need only check that the large trader will not take $v \notin\left\{v\left(\theta_{1}\right), v\left(\theta_{2}\right)\right\}$ when $\theta=\theta_{1}$.

If $v<v\left(\theta_{1}\right)$, then, by definition of $v\left(\theta_{1}\right)$,

$$
\left[\theta_{1}-v\left(\theta_{1}\right)\right]\left[1-\alpha\left(v\left(\theta_{1}\right)\right)\right]>\left(\theta_{1}-v\right)\left[1-\hat{\alpha}\left(v, \theta_{2}\right)\right],
$$

which, because $\hat{\alpha}_{2}>0$, implies that

$$
\left[\theta_{1}-v\left(\theta_{1}\right)\right]\left[1-\alpha\left(v\left(\theta_{1}\right)\right)\right] \geq\left(\theta_{1}-v\right)\left[1-\hat{\alpha}\left(v, \theta_{2}\right)\right],
$$

as desired. If $v>v\left(\theta_{1}\right)$, then, because (A3) holds with equality,

$$
\left[\theta_{2}-v\left(\theta_{1}\right)\right]\left[1-\alpha\left(v\left(\theta_{1}\right)\right)\right] \geq\left(\theta_{2}-v\right)\left[1-\hat{\alpha}\left(v, \theta_{2}\right)\right] .
$$

If $1-\alpha\left(v\left(\theta_{1}\right)\right)<1-\hat{\alpha}\left(v, \theta_{2}\right)$, then (A6) and the fact that $\theta_{1}<\theta_{2}$ imply that (A5) holds. If $1-\alpha\left(v\left(\theta_{1}\right)\right)>1-\hat{\alpha}\left(v, \theta_{2}\right)$, then the fact that $\theta_{2}-v\left(\theta_{1}\right)>\theta_{2}-$ $v$ implies that (A5) holds again. Q.E.D.

\section{Proof of Proposition 3}

For convenience, we shall assume that the solution to (11) is unique, so that $v^{0}\left(\theta_{1}, \theta_{2}\right)$ is well defined. To construct the pooling equilibrium, take $v\left(\theta_{1}\right)=$ $v\left(\theta_{2}\right)=v^{0}\left(\theta_{1}, \theta_{2}\right), \alpha\left(v^{0}\left(\theta_{1}, \theta_{2}\right)\right)=\alpha^{0}\left(v^{0}\left(\theta_{1}, \theta_{2}\right), \theta_{1}, \theta_{2}\right)$, and $g\left(\theta_{2} \mid v^{0}\left(\theta_{1}, \theta_{2}\right)\right)=\pi_{\imath}$, $i=1$, 2. It remains to construct the equilibrium for out-of-equilibrium prices. For any price $v\left(\neq v^{0}\left(\theta_{1}, \theta_{2}\right)\right)$, let $g\left(\theta_{2} \mid v\right)=1$. We must show that, given these beliefs, the large trader will never set such a price if $\theta_{1}$ and $\theta_{2}$ are close enough. Suppose first that $\tilde{\theta}=\theta_{2}$. If $\theta_{1}=\theta_{2}$, then the large trader will not gain by setting $v \neq v^{0}\left(\theta_{1}, \theta_{2}\right)$ since, in this case, $v^{0}\left(\theta_{1}, \theta_{2}\right)=v^{*}\left(\theta_{2}\right)$. Thus it suffices to show that, at $\theta_{1}=\theta_{2}$, the large trader's payoff $\left[\theta_{2}-v^{0}\left(\theta_{1}, \theta_{2}\right)\right][1-$ $\left.\alpha^{0}\left(v^{0}\left(\theta_{1}, \theta_{2}\right), \theta_{1}, \theta_{2}\right)\right]$ is decreasing in $\theta_{1}$, because then

$$
\begin{gathered}
{\left[\theta_{2}-v^{0}\left(\theta_{1}, \theta_{2}\right)\right]\left[1-\alpha^{0}\left(v^{0}\left(\theta_{1}, \theta_{2}\right), \theta_{1}, \theta_{2}\right)\right]} \\
>\left[\theta_{2}-v^{*}\left(\theta_{2}\right)\right]\left[1-\alpha^{*}\left(\theta_{2}\right)\right] \geq\left(\theta_{2}-v\right)\left[1-\hat{\alpha}\left(v, \theta_{2}\right)\right] \text { for all } v
\end{gathered}
$$

when $\theta_{1}$ is near $\theta_{2}$. Now

$$
\begin{gathered}
\frac{d}{d \theta_{1}}\left\{\left[\theta_{2}-v^{0}\left(\theta_{1}, \theta_{2}\right)\right]\left[1-\alpha^{0}\left(v^{0}\left(\theta_{1}, \theta_{2}\right), \theta_{1}, \theta_{2}\right)\right]\right\} \\
\quad=-\left(\theta_{2}-v^{0}\right)\left(\alpha_{1}^{0} v_{1}^{0}+\alpha_{2}^{0}\right)-\left(1-\alpha^{0}\right) v_{1}^{0} .
\end{gathered}
$$

But at $\theta_{1}=\theta_{2}$, the first-order condition for the maximization in (11) is

$$
-\left(\theta_{2}-v^{0}\right) \alpha_{1}^{0}-\left(1-\alpha^{0}\right)=0,
$$

and so the right-hand side of (A7) reduces to

$$
-\left(\theta_{2}-v^{0}\right) \alpha_{2}^{0} \text {. }
$$

Since $\alpha_{2}^{0}>0,(\mathrm{~A} 8)$ is negative at $\theta_{1}=\theta_{2}$, as required.

Assume next that $\tilde{\theta}=\theta_{1}$. In this case, if the large trader failed to set $v=$ $v^{0}\left(\theta_{1}, \theta_{2}\right)$, his best alternative is to choose $v=v^{00}\left(\theta_{1}, \theta_{2}\right)$ that solves the following program:

$$
\max _{v}\left(\theta_{1}-v\right)\left[1-\hat{\alpha}\left(v, \theta_{2}\right)\right]
$$

since $g\left(\theta_{2} \mid v\right)=1$ for all $v \neq v^{0}\left(\theta_{1}, \theta_{2}\right)$. Thus it suffices to show that his gain 
from choosing $v^{0}$ rather than $v^{00}$ is decreasing in $\theta_{1}$ at $\theta_{1}=\theta_{2}$, that is,

$$
\begin{aligned}
& \frac{d}{d \theta_{1}}\left\{\left[\theta_{1}-v^{0}\left(\theta_{1}, \theta_{2}\right)\right]\left[1-\alpha^{0}\left(v^{0}\left(\theta_{1}, \theta_{2}\right), \theta_{1}, \theta_{2}\right)\right]\right. \\
- & {\left.\left[\theta_{1}-v^{00}\left(\theta_{1}, \theta_{2}\right)\right]\left[1-\hat{\alpha}\left(v^{00}\left(\theta_{1}, \theta_{2}\right), \theta_{2}\right)\right]\right\}_{\theta_{1}=\theta_{2}}<0 . }
\end{aligned}
$$

But from the same application of the envelope theorem that we used in the previous paragraph, we can rewrite the left-hand side of (A9) as

$$
-\left(\theta_{1}-v^{0}\right) \alpha_{2}^{0}+1-\alpha^{0}-(1-\hat{\alpha}) .
$$

Now $\alpha^{0}=\hat{\alpha}$ at $\theta_{1}=\theta_{2}$, and $\alpha_{2}^{0}>0$. Hence, (A9) holds, as required. Q.E.D.

\section{Proof of Proposition 4}

Suppose that there exists a pooling equilibrium in which $v\left(\theta_{2}\right)=v$ and $\alpha\left(v\left(\theta_{\imath}\right)\right)$ $=\alpha, i=1$, 2. If $\alpha<1$, then

$$
\begin{gathered}
\pi_{1} E\left(\theta_{1}+\tilde{\boldsymbol{\epsilon}}-v\right) u^{\prime}\left(w_{0}+v+\alpha\left(\theta_{1}+\tilde{\boldsymbol{\epsilon}}-v\right)\right) \\
+\pi_{2} E\left(\theta_{2}+\tilde{\boldsymbol{\epsilon}}-v\right) u^{\prime}\left(w_{0}+v+\alpha\left(\theta_{2}+\tilde{\boldsymbol{\epsilon}}-v\right)\right) \leq 0 .
\end{gathered}
$$

Clearly, $0 \leq v \leq \theta_{1}$. Therefore, the left-hand side of (A10) is no less than

$$
\begin{gathered}
\pi_{1} \int_{\boldsymbol{\epsilon}<0} \boldsymbol{\epsilon} u^{\prime}\left(w_{0}+\boldsymbol{\epsilon}\right) d F(\boldsymbol{\epsilon})+\pi_{1} \int_{\boldsymbol{\epsilon}>0} \boldsymbol{\epsilon} u^{\prime}\left(w_{0}+\theta_{1}+\boldsymbol{\epsilon}\right) d F(\boldsymbol{\epsilon}) \\
+\pi_{2} E\left(\theta_{2}+\tilde{\boldsymbol{\epsilon}}-\theta_{1}\right) u^{\prime}\left(w_{0}+(1-\alpha) \theta_{1}+\alpha\left(\theta_{2}+\tilde{\boldsymbol{\epsilon}}\right)\right) .
\end{gathered}
$$

The first two terms of (A11) are independent of $\theta_{2}$. Denote them by $K$. As $\theta_{2}$ tends to infinity, so does the third term, thanks to our hypothesis about $u$. Thus eventually the third term exceeds $|K|$, a contradiction of (A10). Hence, $\alpha=1$, and so the large trader's payoff is zero when $\tilde{\theta}=\theta_{2}$. But since $\alpha^{*}\left(\theta_{2}\right)$ $<1$ by hypothesis, he can obtain a positive payoff by setting $v=v^{*}\left(\theta_{2}\right)$, a contradiction. Q.E.D.

\section{Proof of Proposition 5}

Consider a $\operatorname{BPBE}(v(\cdot), \alpha(\cdot), g(\cdot \mid \cdot))$. From proposition 1,

$$
\max \left\{v \mid v \in \text { support of } v\left(\theta_{1}\right)\right\} \leq \min \left\{v \mid v \in \text { support of } v\left(\theta_{2}\right)\right\} \text {. }
$$

Suppose first that (A12) is strict. Then the small traders are perfectly informed about $\theta$ by price. For $i=1,2$, choose $v_{\imath} \in$ support of $v\left(\theta_{\imath}\right)$ such that $U\left(\theta_{i}, \alpha\left(v_{\imath}\right), v_{\imath}\right) \geq U\left(\theta_{i}, \alpha\left(v_{l}^{\prime}\right), v_{i}^{\prime}\right)$ for all $v_{i}^{\prime} \in$ support of $v\left(\theta_{\imath}\right)$. But then we can define a deterministic $\operatorname{PBE}(\bar{v}(\cdot), \bar{\alpha}(\cdot), \bar{g}(\cdot \mid \cdot))$ where, for $i=1,2, \bar{v}\left(\theta_{i}\right)=v_{\imath}$ (and $\bar{\alpha}(\cdot)=\alpha(\cdot)$ and $\bar{g}(\cdot \mid \cdot)=g(\cdot \mid \cdot))$ in which the large trader is as well off as before since he is indifferent among all prices in the support of $v\left(\theta_{2}\right)$.

Suppose henceforth that (A12) holds with equality and that both sides equal $\bar{v}$. If $\bar{v}$ is not a mass point of $v\left(\theta_{1}\right)$ and $v\left(\theta_{2}\right)$, the argument of the preceding paragraph applies. Assume, therefore, that $\operatorname{Pr}\left\{v\left(\theta_{i}\right)=\bar{v}\right\}>0$ for $i$ $=1,2$.

\section{Case 1: Only $v\left(\theta_{1}\right)$ Is Random}

In this case, $v\left(\theta_{2}\right)=\bar{v}$. Define $\bar{v}(\cdot)$ so that $\bar{v}\left(\theta_{i}\right)=\bar{v}$ for $i=1$, 2. Define $\bar{g}(\cdot \mid \cdot)$ so that $\bar{g}\left(\theta_{\imath} \mid \bar{v}\right)=\pi_{\imath}, i=1,2$, and $\bar{g}(\cdot \mid v)=g(\cdot \mid v)$ for $v \neq \bar{v}$. Finally, let $\bar{\alpha}(\bar{v})=$ 
$\alpha^{0}\left(\bar{v}, \theta_{1}, \theta_{2}\right)$ and $\bar{\alpha}(v)=\alpha(v)$ for $v \neq \bar{v}$. Because $\bar{g}\left(\theta_{1} \mid \bar{v}\right)>g\left(\theta_{1} \mid \bar{v}\right), \bar{\alpha}(\bar{v})<\alpha(\bar{v})$ from the lemma. Thus the large trader has no incentive to deviate from $\bar{v}$; that is, $(v(\cdot), \alpha(\cdot), g(\cdot \mid \cdot))$ is an equilibrium. Moreover, the large trader does better in this equilibrium than in the orginal equilibrium, regardless of the value of $\tilde{\theta}$.

\section{Case 2: $v\left(\theta_{2}\right)$ Is Random}

Because $g\left(\theta_{1} \mid \bar{v}\right)<1$, the lemma implies that $\alpha(\bar{v})>\hat{\alpha}\left(\bar{v}, \theta_{1}\right)$. Hence, there exists $v_{1}<\bar{v}$ such that $\left[1-\hat{\alpha}\left(v_{1}, \theta_{1}\right)\right]\left(\theta_{1}-v_{1}\right)$ is the payoff that the large trader gets in equilibrium if $\tilde{\theta}=\theta_{1}$. Thus $\hat{\alpha}\left(v_{1}, \theta_{1}\right)>\alpha\left(\theta_{1}\right)$, and so

$$
\left(\theta_{2}-\bar{v}\right)[1-\alpha(\bar{v})]>\left(\theta_{2}-v_{1}\right)\left[1-\hat{\alpha}\left(v_{1}, \theta_{1}\right)\right] .
$$

Choose $v_{2} \in$ support of $v\left(\theta_{2}\right)$ with $v_{2}>\bar{v}$. Define $(\bar{v}(\cdot), \bar{\alpha}(\cdot), \bar{g}(\cdot \mid \cdot))$ so that

$$
\begin{aligned}
\left(v\left(\theta_{1}\right), \bar{\alpha}\left(\bar{v}_{1}\right), \bar{g}\left(\theta_{1} \mid v_{1}\right)\right) & =\left(v_{1}, \hat{\alpha}\left(v_{1}, \theta_{1}\right), 1\right), \\
\left(v\left(\theta_{2}\right), \bar{\alpha}\left(v_{2}\right), \bar{g}\left(\theta_{2} \mid v_{2}\right)\right) & =\left(v_{2}, \alpha\left(v_{2}\right), 1\right), \\
\bar{\alpha}(v) & =\hat{\alpha}\left(v, \theta_{2}\right) \text { for } v \notin\left\{v_{1}, v_{2}\right\}, \\
\bar{g}\left(\theta_{2} \mid v\right) & =1 \text { for } v \notin\left\{v_{1}, v_{2}\right\} .
\end{aligned}
$$

This construction satisfies the large trader's incentive constraints (condition iii of the definition of PBE) when $\tilde{\theta}=\theta_{1}$ since his payoff is the same as in the original PBE and, thanks to the lemma and to the definition of $\bar{g}(\cdot \mid \cdot), \bar{\alpha}(v)$ $\geq \alpha(v)$ for all $v \neq \bar{v}\left(\theta_{1}\right)$. Moreover, it also satisfies his incentive constraints when $\tilde{\theta}=\theta_{2}$ because

$$
\begin{gathered}
\left(\theta_{2}-v_{2}\right)\left[1-\bar{\alpha}\left(v_{2}\right)\right]=\left(\theta_{2}-\bar{v}\right)[1-\alpha(\bar{v})] \\
>\left(\theta_{2}-v_{1}\right)\left[1-\hat{\alpha}\left(v_{1}, \theta_{1}\right)\right]=\left(\theta_{2}-v_{1}\right)\left[1-\bar{\alpha}\left(v_{1}\right)\right],
\end{gathered}
$$

where the two equations follow from construction and the inequality follows from (A13). Hence, $(\bar{v}(\cdot), \bar{\alpha}(\cdot), \bar{g}(\cdot \mid \cdot))$ is an equilibrium and, hence, a deterministic BPBE. Q.E.D.

\section{Proof of Proposition 9}

We first observe that, in any separating equilibrium $(v(\cdot), \alpha(\cdot), g(\cdot \mid \cdot)), v\left(\theta_{2}\right)=$ $v^{*}\left(\theta_{2}\right)$. This follows since $v=v^{*}\left(\theta_{2}\right)$ maximizes $\left(\theta_{2}-v\right)\left[1-\hat{\alpha}\left(v, \theta_{2}\right)\right]$ and, from the large trader's standpoint, the most disadvantageous beliefs that the small traders could have are $g\left(\theta_{2} \mid v\right)=1$.

From the proof of proposition 6 , the separating equilibrium $\left(v^{*}(\cdot), \alpha^{*}(\cdot)\right.$, $\left.g^{*}(\cdot \mid \cdot)\right)$ that solves program (12)-(13) satisfies (13) with equality when $\theta_{1}$ is near enough $\theta_{2}$. Moreover, as the proof shows, (13) is violated for $\left(v_{1}, v_{2}\right)$ such that $v_{2}=v^{*}\left(\theta_{2}\right)=v^{*}\left(\theta_{2}\right)$ and $v^{*}\left(\theta_{1}\right)<v_{1} \leq v^{*}\left(\theta_{2}\right)=v^{*}\left(\theta_{2}\right)$. Hence, for $\theta_{1}$ near $\theta_{2}$, any separating equilibrium $(v(\cdot), \alpha(\cdot), g(\cdot \mid \cdot))$ must satisfy $v_{2}\left(\theta_{2}\right)=$ $v^{*}\left(\theta_{2}\right)$ and $v_{1}\left(\theta_{1}\right) \leq v^{*}\left(\theta_{1}\right)$. But for a small trader, a higher price is unambiguously better than a lower price. Thus $\left(v^{*}(\cdot), \alpha^{*}(\cdot), g^{*}(\cdot \mid \cdot)\right)$ is the small traders' favorite separating equilibrium, and it suffices to show that they consider this equilibrium inferior to the pooling equilibrium defined by (11).

When $\theta_{1}=\theta_{2}$, the small traders are, of course, indifferent between the two equilibria. Thus we need demonstrate only that the derivative of the small traders' payoff with respect to $\theta_{1}$ at $\theta_{1}=\theta_{2}$ is greater for the separating than for the pooling equilibrium. For the separating equilibrium $\left(v^{*}(\cdot), \alpha^{*}(\cdot)\right.$, 
$\left.g^{*}(\cdot \mid \cdot)\right)$, we have

$$
\begin{aligned}
& \frac{d}{d \theta_{1}} \sum_{\imath} \pi_{\imath} E u\left(w_{0}+v^{*}\left(\theta_{\imath}\right)+\left[\theta_{i}+\tilde{\boldsymbol{\epsilon}}-v^{*}\left(\theta_{i}\right)\right] \hat{\alpha}\left(v^{*}\left(\theta_{\imath}\right), \theta_{2}\right)\right) \\
&=\pi_{1} E u^{\prime}\left[\left\{1-\hat{\alpha}+\left[\theta_{1}+\tilde{\boldsymbol{\epsilon}}-v^{*}\left(\theta_{1}\right)\right] \hat{\alpha}_{1}\right\} \frac{d v^{*}\left(\theta_{1}\right)}{d \theta_{1}}\right. \\
&\left.+\left[\theta_{1}+\tilde{\boldsymbol{\epsilon}}-v^{*}\left(\theta_{1}\right)\right] \hat{\alpha}_{2}\left(v^{*}\left(\theta_{1}\right), \theta_{1}\right)+\hat{\alpha}\left(v^{*}\left(\theta_{1}\right), \theta_{1}\right)\right] .
\end{aligned}
$$

Because (13) holds with equality,

$$
\frac{d}{d \theta_{1}}\left[\theta_{2}-v^{*}\left(\theta_{1}\right)\right]\left[1-\hat{\alpha}\left(v^{*}\left(\theta_{1}\right), \theta_{1}\right)\right]=0,
$$

and so

$$
\left\{1-\hat{\alpha}+\left[\theta_{2}-v^{*}\left(\theta_{1}\right)\right] \hat{\alpha}_{1}\right\} \frac{d v^{*}}{d \theta_{1}}+\left[\theta_{2}-v^{*}\left(\theta_{1}\right)\right] \hat{\alpha}_{2}=0 .
$$

Now $v *\left(\theta_{2}\right)$ maximizes $\left(\theta_{2}-v\right)\left[1-\hat{\alpha}\left(v, \theta_{2}\right)\right]$. Thus

$$
\left[\theta_{2}-v^{*}\left(\theta_{2}\right)\right] \hat{\alpha}_{1}\left(v^{*}\left(\theta_{2}\right), \theta_{2}\right)+1-\hat{\alpha}\left(v^{*}\left(\theta_{2}\right), \theta_{2}\right)=0 .
$$

But at $\theta_{1}=\theta_{2}, v^{*}\left(\theta_{1}\right)=v^{*}\left(\theta_{2}\right)$, and so from (A16), the coefficient of $d v^{*} / d \theta_{1}$ in (A15) is zero. Thus from (A15),

$$
\left.\frac{d v^{*}\left(\theta_{1}\right)}{d \theta_{1}}\right|_{\theta_{1}=\theta_{2}}=\infty
$$

From (A15), the right-hand side of (A14) simplifies at $\theta_{1}=\theta_{2}$ to

$$
\pi_{1} E u^{\prime}\left[\tilde{\epsilon} \hat{\alpha}_{1} \frac{d v^{*}}{d \theta_{1}}+\tilde{\epsilon} \hat{\alpha}_{2}+\hat{\alpha}\right] \text {. }
$$

From (A16), $\hat{\alpha}_{1}<0$. Hence, in view of (A17) and because $E \tilde{\epsilon} u^{\prime}<0,(\mathrm{~A} 18)$ is $\infty$, and so the derivative of the small traders' payoff is infinite.

By contrast, the derivative of the small traders' payoff at $\theta_{1}=\theta_{2}$ in the pooling equilibrium is

$$
\begin{gathered}
\frac{d}{d \theta_{1}} \sum_{\imath} \pi_{\imath} E u\left(v^{0}\left(\theta_{1}, \theta_{2}\right)+\left[\theta_{\imath}+\tilde{\boldsymbol{\epsilon}}-v^{0}\left(\theta_{1}, \theta_{2}\right)\right] \alpha^{0}\left(v^{0}\left(\theta_{1}, \theta_{2}\right), \theta_{1}, \theta_{2}\right)\right) \\
=\sum_{\imath} \pi_{\imath} E u^{\prime}\left[\left(1-\alpha^{0}\right) \frac{\partial v^{0}}{\partial \theta_{1}}\right]+\pi_{1} E u^{\prime} \alpha^{0}
\end{gathered}
$$

where $v^{0}\left(\theta_{1}, \theta_{2}\right)$ maximizes $\Sigma_{\imath} \pi_{\imath}\left(\theta_{\imath}-v\right)\left[1-\alpha^{0}\left(v, \theta_{1}, \theta_{2}\right)\right]$. The first-order condition for this maximization is

$$
\sum_{\imath} \pi_{\imath}\left[\left(\theta_{\imath}-v^{0}\right) \alpha_{1}^{0}+1-\alpha^{0}\right]=0
$$

Implicitly differentiating (A20) with respect to $\theta_{1}$, we obtain

$$
\sum_{\imath} \pi_{\imath}\left\{\left[\left(\theta_{\imath}-v^{0}\right) \alpha_{11}^{0}-2 \alpha_{1}^{0}\right] \frac{\partial v^{0}}{\partial \theta_{1}}+\left(\theta_{\imath}-v^{0}\right) \alpha_{12}^{0}-\alpha_{2}^{0}\right\}+\pi_{1} \alpha_{1}^{0}=0,
$$


and hence

$$
\frac{\partial v^{0}}{\partial \theta_{1}}=\frac{-\pi_{1} \alpha_{1}^{0}-\sum_{\imath} \pi_{\imath}\left[\left(\theta_{\imath}-v^{0}\right) \alpha_{12}^{0}-\alpha_{2}^{0}\right]}{\sum_{\imath} \pi_{\imath}\left[\left(\theta_{\imath}-v^{0}\right) \alpha_{11}^{0}-2 \alpha_{1}^{0}\right]} .
$$

But (A21) is clearly finite, and thus so is (A19). Hence the derivative for the separating equilibrium is bigger, as required. Q.E.D

\section{References}

Allen, Beth E. "Generic Existence of Completely Revealing Equilibria for Economies with Uncertainty When Prices Convey Information." Econometrica 49 (September 1981): 1173-99.

Altug, Sumru. "The Effect of Insider Trading by a Dominant Trader in a Simple Securities Market Model." Discussion Paper no. 212. Minneapolis: Univ. Minnesota, 1985.

Arrow, Kenneth J. Essays in the Theory of Risk-Bearing. Amsterdam: NorthHolland, 1971.

Baesel, Jerome B., and Stein, Garry R. "The Value of Information: Inferences from the Profitability of Insider Trading." J. Financial and Quantitative Analysis 14 (September 1979): 553-71.

Cripps, M. "Specialist Pricing in Asset Markets with Asymmetric Information." Manuscript. London: London School Econ., 1986.

Dann, Larry Y.; Mayers, David; and Raab, Robert J., Jr. "Trading Rules, Large Blocks and the Speed of Price Adjustment." J. Financial Econ. 4 (January 1977): 3-22.

Gould, John P., and Verrecchia, Robert E. "The Information Content of Specialist Pricing." J.P.E. 93 (February 1985): 66-83.

Grier, Paul C., and Albin, Peter S. "Nonrandom Price Changes in Association with Trading in Large Blocks." J. Bus. 46 (July 1973): 425-33.

Grinblatt, Mark S., and Ross, Stephen A. "Market Power in a Securities Market with Endogenous Information." Q.J.E. 100 (November 1985): 114367.

Grossman, Sanford J. "On the Efficiency of Competitive Stock Markets Where Traders Have Diverse Information." J. Finance 31 (May 1976): 57385.

Jaffe, Jeffrey F. "Special Information and Insider Trading." J. Bus. 47 (July 1974): 410-28.

Kihlstrom, Richard, and Postlewaite, Andrew. "Equilibrium in a Securities Market with a Dominant Trader Possessing Inside Information." Manuscript. Philadelphia: Univ. Pennsylvanią, 1983.

Kraus, Alan, and Stoll, Hans R. "Price Impacts of Block Trading on the New York Stock Exchange." J. Finance 27 (June 1972): 569-88.

Kyle, Albert S. "Continuous Auctions and Insider Trading." Econometrica 53 (November 1985): 1315-35.

Laffont, Jean-Jacques, and Maskin, Eric S. "Rational Expectations with Imperfect Competition, I: Monopoly." Discussion paper. Cambridge, Mass.: Harvard Univ., Inst. Econ. Res., 1987.

Lorie, James H., and Niederhoffer, Victor. "Predictive and Statistical Properties of Insider Trading." J. Law and Econ. 11 (April 1968): 35-53. 
Niederhoffer, Victor, and Osborne, M. F. M. "Market Making and Reversal on the Stock Exchange." J. American Statis. Assoc. 61 (December 1966): 897-916.

Radner, Roy. "Rational Expectations Equilibrium: Generic Existence and the Information Revealed by Prices." Econometrica 47 (May 1979): 655-78.

Rothschild, Michael, and Stiglitz, Joseph E. "Increasing Risk: I. A Definition." J. Econ. Theory 2 (September 1970): 225-43.

Scholes, Myron S. "The Market for Securities: Substitution versus Price Pressure and the Effects of Information on Share Prices." J. Bus. 45 (April 1972): 179-211. 
http://www.jstor.org

\title{
LINKED CITATIONS
}

- Page 1 of 2 -

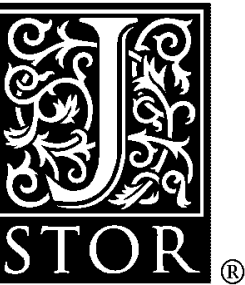

You have printed the following article:

The Efficient Market Hypothesis and Insider Trading on the Stock Market

Jean-Jacques Laffont; Eric S. Maskin

The Journal of Political Economy, Vol. 98, No. 1. (Feb., 1990), pp. 70-93.

Stable URL:

http://links.jstor.org/sici?sici=0022-3808\%28199002\%2998\%3A1\%3C70\%3ATEMHAI\%3E2.0.CO\%3B2-W

This article references the following linked citations. If you are trying to access articles from an off-campus location, you may be required to first logon via your library web site to access JSTOR. Please visit your library's website or contact a librarian to learn about options for remote access to JSTOR.

\section{References}

Generic Existence of Completely Revealing Equilibria for Economies with Uncertainty when Prices Convey Information

Beth Allen

Econometrica, Vol. 49, No. 5. (Sep., 1981), pp. 1173-1199.

Stable URL:

http://links.jstor.org/sici?sici=0012-9682\%28198109\%2949\%3A5\%3C1173\%3AGEOCRE\%3E2.0.CO\%3B2-7

\author{
Nonrandom Price Changes in Association with Trading in Large Blocks \\ Paul C. Grier; Peter S. Albin \\ The Journal of Business, Vol. 46, No. 3. (Jul., 1973), pp. 425-433. \\ Stable URL: \\ http://links.jstor.org/sici?sici=0021-9398\%28197307\%2946\%3A3\%3C425\%3ANPCIAW\%3E2.0.CO\%3B2-W
}

\author{
On the Efficiency of Competitive Stock Markets Where Trades Have Diverse Information \\ Sanford Grossman \\ The Journal of Finance, Vol. 31, No. 2, Papers and Proceedings of the Thirty-Fourth Annual \\ Meeting of the American Finance Association Dallas, Texas December 28-30, 1975. (May, 1976), \\ pp. 573-585. \\ Stable URL: \\ http://links.jstor.org/sici?sici=0022-1082\%28197605\%2931\%3A2\%3C573\%3AOTEOCS\%3E2.0.CO\%3B2-Y
}


http://www.jstor.org

\section{LINKED CITATIONS \\ - Page 2 of 2 -}

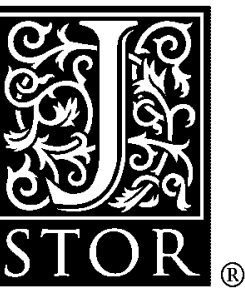

\section{Special Information and Insider Trading}

Jeffrey F. Jaffe

The Journal of Business, Vol. 47, No. 3. (Jul., 1974), pp. 410-428.

Stable URL:

http://links.jstor.org/sici?sici=0021-9398\%28197407\%2947\%3A3\%3C410\%3ASIAIT\%3E2.0.CO\%3B2-9

Price Impacts of Block Trading on the New York Stock Exchange

Alan Kraus; Hans R. Stoll

The Journal of Finance, Vol. 27, No. 3. (Jun., 1972), pp. 569-588.

Stable URL:

http://links.jstor.org/sici?sici=0022-1082\%28197206\%2927\%3A3\%3C569\%3APIOBTO\%3E2.0.CO\%3B2-I

Continuous Auctions and Insider Trading

Albert S. Kyle

Econometrica, Vol. 53, No. 6. (Nov., 1985), pp. 1315-1335.

Stable URL:

http://links.jstor.org/sici?sici=0012-9682\%28198511\%2953\%3A6\%3C1315\%3ACAAIT\%3E2.0.CO\%3B2-8

Rational Expectations Equilibrium: Generic Existence and the Information Revealed by Prices

Roy Radner

Econometrica, Vol. 47, No. 3. (May, 1979), pp. 655-678.

Stable URL:

http://links.jstor.org/sici?sici=0012-9682\%28197905\%2947\%3A3\%3C655\%3AREEGEA\%3E2.0.CO\%3B2-X

The Market for Securities: Substitution Versus Price Pressure and the Effects of Information on Share Prices

Myron S. Scholes

The Journal of Business, Vol. 45, No. 2. (Apr., 1972), pp. 179-211.

Stable URL:

http://links.jstor.org/sici?sici=0021-9398\%28197204\%2945\%3A2\%3C179\%3ATMFSSV\%3E2.0.CO\%3B2-M 